\title{
Between Archive and Participation: Public Memory in a Digital Age
}

\author{
Ekaterina Haskins \\ Language, Literature, and Communication, Rensselaer Polytechnic \\ Institute, Troy, New York, USA
}

\begin{abstract}
In sizing up the notion of public memory, rhetoricians would be remiss not to consider the increasing influence of new media on today's remembrance culture. This article addresses memorial functions of the internet in light of recent scholarly debates about virtues and drawbacks of modern "archival memory" as well as the paradoxical link between the contemporary public obsession with memory and the acceleration of amnesia. To explore the strengths and limitations of the internet as a vehicle of collecting, preserving, and displaying traces of the past, the article examines The September 11 Digital Archive, a comprehensive online effort to document public involvement in recording and commemorating the tragedy of 11 September, 2001.
\end{abstract}

In sizing up the notion of public memory, rhetoricians would be remiss not to consider the increasing importance of new media in shaping our contemporary remembrance culture. Whereas mediation in one form or another has always imprinted itself on memory work, the rising popularity of the internet as a vehicle of memory and as a supplement to older forms of commemoration deserves a closer look. This article proposes to examine memorial functions of the internet in light of recent scholarly debates about virtues and drawbacks of modern "archival memory" as well as the paradoxical link between the contemporary public obsession with memory and the acceleration of amnesia. I suggest that "digital memory," more than any other form of mediation, collapses the assumed distinction between modern "archival" memory and traditional "lived" memory by combining the function of storage and ordering on the one hand, and of presence and interactivity on

Address correspondence to Ekaterina Haskins, Language, Literature, and Communication, Rensselaer Polytechnic Institute, SA 4th Floor, 110 8th Street, Troy, NY 12180, USA. E-mail: haskie@rpi.edu 
the other. Although on its face such synthesis seems to posit the internet as a panacea for both ideological reification associated with official memory practices and the fragility of popular memory, the medium's potential cannot be discussed in the abstract, separate from its cultural and political milieu and institutions that have deployed it in the service of memory work. Accordingly, to illustrate the merits and limitations of electronic media as vehicles of collecting, preserving, and displaying traces of the past, I will examine The September 11 Digital Archive, a comprehensive online effort to document public involvement in commemorating the tragedy of 11 September 2001.

\section{Archival Memory and lts Discontents}

In his influential work The Past is a Foreign Country, David Lowenthal remarks, "The past is integral to our sense of identity.... Ability to recall and identify with our own past gives existence meaning, purpose, and value" (41). Although most public memory scholars begin with this premise as a point of departure, their analyses of commemorative activity often raise questions of representation and agency. Which past is identified as worthy of remembrance? Who carries out the work of recalling it? What forms does commemoration take?

As French historian Pierre Nora famously observed, "Modern memory is, above all, archival. It relies entirely on the materiality of the trace, the immediacy of the recording, the visibility of the image" (13). In choosing what to preserve as traces of the past, museums and archives have traditionally valued objects and texts, selected for their enduring cultural value, over ephemeral manifestations of cultural heritage. Not incidentally, artifacts and texts selected for preservation and veneration were typically products of intellectual and artistic elites rather than illiterate artisans and performers. This preference, furthermore, contributed to the loss of contexts in which artifacts and texts were produced in order to subordinate them to legitimizing narratives of historical progress and national identity. ${ }^{1}$

Furthermore, relegating the task of remembering to official institutions and artifacts arguably weakens the need for a political community actively to remember its past. Instead of continuous transmission of shared past through participatory performance and ritual, memory work is carried out by "compensatory organs of remembrance" (Huyssen 252) such as museums, archives, and memorials. ${ }^{2}$ Associated with the rise of capitalism and the modern nation-state, these institutions of memory have tended to promulgate official ideologies of the ruling elites while claiming to speak on behalf of the people. As John Gillis points out, until the late 1960s, memory work 
was "the preserve of elite males, the designated carriers of progress .... Workers, racial minorities, young people, and women gained admission to national memories at an even slower pace than they were admitted to national representative and educational institutions" (10). In other words, until recently, public memory was constructed and disseminated for the people but not by the people.

Stylistically, official memorial culture has relied on "dogmatic formalism' and the restatement of reality in ideal rather than complex or ambiguous forms" (Bodnar 13). Monuments and memorials erected throughout the nineteenth and first half of the twentieth centuries employed representational symbolism to convey narratives of victory and valor. ${ }^{3}$ Museums of history and public art, similarly, were fashioned after Greek and Roman architectural forms to emphasize the affinities between modern nation-state and classical forms of government (Duncan). The scale of memorials and museums, too, played its role in instilling a sense of awe and distance in their audience: dwarfed by their size, the visitor was cast in the role of observer and spectator rather than participant.

In contrast with the hegemonic official memory, vernacular practices of public remembrance typically assume decidedly ephemeral forms such as parades, performances, and temporary interventions. Instead of somber monumentality, they employ non-hierarchical, sometimes subversive symbolism and stress egalitarian interaction and participation. According to Bodnar, such practices convey "what social reality feels like rather than what it should be like" (14). Although vernacular forms of cultural expression have existed alongside the official culture for a long time (think of Medieval carnival), it is only recently that they acquired cultural respectability in Western democracies. The traveling NAMES project AIDS Memorial quilt is often cited as an example of a vernacular commemoration that acts both as an intimate tableau of private grief and a compelling form of public address. The multiplicity of individually crafted panels comprising the Quilt as well as the variety of messages and images inscribed on them underscored the plurality of voices united in the act of grieving and the enormity of the problem that the audience was encouraged to grasp. The quilt's material and its formal configuration also made a vivid statement: fabric by nature frays and decays with time, so fresh panels must replace the worn ones and new panels must be added as more lives are claimed by the AIDS epidemic (Hawkins 141). By its very impermanence and contingency, then, this memorial gesture reminded its audience about the frailty of memory and its dependence on the continuing communal participation.

The line between official and vernacular memory practices, however, is becoming blurry, as designers, museum professionals and 
art critics begin to ponder how "permanent" memorials might engage their popular audiences instead of imposing on them the ossified values of political and cultural elites. Many scholars agree that official "archival" memory no longer exclusively relies on idealized representational forms and dogmatic iconography. Projection artist Krzystof Wodiczko, a champion of ephemeral public gestures, describes this shift from official to vernacular tendencies in public memorials:

The previously respectful distance ("historical perspective") of the memorial from everyday life is now being broken. Cold, tombstone benches, regimenting, mountainous stairways, brainwashing fountains, architortured bushes, and windswept floors were intended to banish unofficial life from the memorial's territory. Today, the authorities want to add life and "social function" to the memorial site, to turn it into a "humanized" space for cultural relaxation, a zone of free festivity, tourism, permanent recreation, and so-called art in public spaces. (49)

The precedent, at least in the United States, appears to have been set by Maya Lin's design for the Vietnam Veterans Memorial in Washington, D.C. Instead of glorifying the Vietnam conflict, the black granite chevron laconically conveys the cost of war by listing all American casualties in chronological order. Explaining its impact on subsequent commemorations, Gillis states, "the Vietnam Memorial, with its wall of names is generally agreed to represent a turning point in the history of public memory, a decisive departure from the anonymity of the Tomb of the Unknown Soldier and a growing acknowledgement that everyone now deserves equal recognition at all times in wholly accessible places" (13).

In addition to its strategy of naming names, the memorial's physical form invites participation: its polished black surface reflects the visitor's image and its modest scale allows one to reach out and touch the names inscribed on the wall. Although its non-heroic stance initially angered some officials and veterans who wished to see an unambiguous affirmation of military valor, the memorial has become an iconic site of popular remembrance. To mark their pilgrimage to the wall, many visitors leave behind mementos that temporarily become part of the memorial composition. At first, the National Park Service classified these ephemera as "lost and found" but later on began collecting and archiving them for posterity, thus moving them "from the cultural status of being 'lost' (without category) to historical artifacts" (Sturken 173). In the case of the Vietnam Veterans Memorial, then, "written in stone" official memory and ephemeral public participation are continuous with each other. ${ }^{4}$ This happy coexistence 
seems to guard against the twin dangers of ideological reification and amnesia. In the age of electronic media, however, these dangers haunt all efforts to include the public into the memorial process and to preserve the ephemera of popular expression.

\section{Promises and Problems of Digital Memory}

Although even "permanent" memorials and museums are now being built with an eye to stimulating public engagement, their capacity to share memory work with ordinary people pales in comparison with "digital" memorials and archives. Still, the internet's promise of representational diversity, collective authorship, and interactivity is in need of exploration and critique.

At least in theory, online memorializing can accommodate an infinite variety of artifacts and performances. Because all new media objects are composed of digital code (Manovich 27), it becomes possible to collect, preserve, sort, and display a vast amount of texts, drawings, photography, video, and audio recordings. In addition to this capacity to "translate" other media into digital code, the function of hyperlinking facilitates interconnectedness among different sources, producing a cacophonous heteroglossia of public expression (Warnick, Critical Literacy 107). Instead of only official accounts disseminated by mainstream media and the government, all kinds of stories can now become part of an evolving patchwork of public memory. Formerly limited in time and space, ephemeral gestures can be preserved in still and moving images, ready to be viewed and replayed on demand. Previously banished to dark storage rooms, mementos left at memorial sites can be displayed for all to see. The boundaries between the official and the vernacular, the public and the private, the permanent and the evanescent will cease to matter, for all stories and images will be equally fit to represent and comment on the past.

Perhaps like no other medium before, the internet has made collective authorship a practical reality, fulfilling many literary critics' desire to free texts from authorial constraints. Most new media texts are products of collaboration among multiple designers and users. According to Warnick, "A hyperlinked, multi-media site including user contributions as part of its text is best described in Barthes' words as a de-centered "tissue of quotations drawn from innumerable centers of culture" (Image 146). It functions as "Text" and not as "work," in that it appropriates and reproduces content from the networked system of which it is a part and may not lend itself well to critical approaches that assume authorial intent and linear structure" ("Looking to the Future" 330-331). Landow elaborates this point when he compares the process of generating digital hypertext with the tradition of 
appropriating or paraphrasing other discourses in print: "The text of the Other may butt up against that by someone else; it may even crash against it. But it does seem to retain more of its own voice. In print, on the other hand, one feels constrained to summarize large portions of another's text, if only to demonstrate one's command (understanding) of it and to avoid giving the appearance that one has infringed copyright" (158). The internet levels the traditional hierarchy of authortext-audience, thereby distributing authorial agency among various institutions and individuals involved in the production of content and preventing any one agent from imposing narrative and ideological closure upon the data. As Web memorials depend on "the joint production of Web-accessible materials by disparate actors" (Foot, Warnick, and Schneider), they represent an evolving, multidimensional narrative of historical events and responses to them.

Similar to multiple authorship, "interactivity" has been hailed as a democratizing attribute of new media. Simply put, interactivity embodies "one of the biggest potentials of cyberspace"- to act as "a two-way street in a world where the dominant medium (television) has been unidirectional" (Gurak 44). Although some consider the term itself too broad and even misleading, ${ }^{5}$ the users' ability to supply content, provide feedback, and choose their own paths through the system of hyperlinks marks the experience of navigating the internet as more participatory and active than that of flipping through television channels, scanning a newspaper, or following an audio-tour through a museum. The audience no longer acts as a consumer of a linear story - it takes part in the experience by making choices to connect particular messages and images as well as to register responses to them.

Although diversity of content, collective authorship, and interactivity hold a potential of stimulating broad public engagement in memory work, these features work in tandem with a larger cultural context and are subject to medium-specific constraints. One cannot ignore that today's memorializing occurs in a climate of rapid obsolescence and the disappearance of historical consciousness, that much of computermediated communication serves commercial and entertainment purposes, and that interactivity can nurture narcissistic amnesia no less than communal exchange.

Contemporary "democratization of the past" (Gillis) is paradoxically entwined with the disappearance of historical consciousness. According to Andreas Huyssen,

Both personal and social memory today are affected by an emerging new structure of temporality generated by the quickening pace of material life on the one hand and by the acceleration of media images and information 
on the other. Speed destroys space, and it erases temporal distance. In both cases, the mechanism of physiological perception is altered. The more memory we store on data banks, the more past is sucked into the orbit of the present, ready to be called up on the screen. (253)

The glut of archival memory is a by-product of rapid obsolescence. In the words of Gillis, "The past has become so distant and the future so uncertain that we can no longer be sure what to save, so we save everything....The scale of collecting increases in inverse proportion to our depth perception. Now that old is equated with yesterday we allow nothing to disappear" (15). The common worry about this expanding dossier is that active memory work-not just compulsive collection of traces - would be thwarted by the sheer volume of stuff that is being preserved as well as the ease of retrieving the past at will. When technology offers the ability of instant recall, individual impulse to remember withers away. If archival preservation and retrieval are not balanced by mechanisms that stimulate participatory engagement, electronic memory may lead to self-congratulatory amnesia. ${ }^{6}$

Another concern is that the typical user's participation in online interaction has been to a large extent shaped by commercial patterns of experience. As Manovich reminds us, "the logic of new media fits the logic of the postindustrial society, which values individuality over conformity" (41). The rhetoric of individual choice permeates contemporary commercial culture, reassuring consumers of their uniqueness and stimulating compulsive shopping as a form of identity-shaping performance. Perhaps it is not coincidental that a good portion of user-supplied Web content consists of self-expression, most vividly represented by the genre of Weblog (Miller and Shepherd). Although some bloggers engage in a sort of editorial activity by providing links and annotating other sources, the majority of blog authors relate their own experiences (whether real or imaginary) to a potentially limitless number of people (Blood).

Blogging can be seen as a form of self-memorialization, and an impulse to save the most trivial details of one's past, however recent it might be, is one of manifestations of contemporary remembrance culture in the West: "Both Americans and Europeans have become compulsive consumers of the past, shopping for that which best suits their particular sense of self at the moment, constructing out of a bewildering variety of materials, times, and places the multiple identities that are demanded of them in the post-national era" (Gillis 17-18).

However, this "customized" approach to one's past and sense of belonging, enabled by electronic media, may breed cultural and political insularity and lead to a fragmented body politic. Scholars of 
political communication caution that some of the internet's assets as a political medium could also be its greatest weaknesses. The ability to narrow down one's Web search thematically, for example, while allowing to magnify one's exposure to information on a particular topic, simultaneously promotes a narrow focus on certain issues at the expense of a broad awareness of political matters (see Selnow, Gronbeck). ${ }^{7}$

The intersection of contemporary remembrance culture and new media technologies presents a mixed bag of promises and problems. Storage and sorting capacities of the internet are certainly helpful in preserving, organizing, and linking vast amounts of data. Everyone can now engage in a free search for one's past and identity, becoming her own historian. Thanks to interactivity, virtually everyone can also leave an imprint on the fabric of public memory by sharing images and stories with millions of other users. As a result of these technologically abetted cultural changes, professional historians, archivists, and museum curators find themselves compelled both to acknowledge the role of ordinary people in history making and to include diverse forms of popular expression into the "official" record of history. In so doing, however, they are facing a challenge to their traditional role as stewards of public memory. To remain relevant, they must strike a delicate balance, as it were, between a desire to accommodate as many different voices as possible, on the one hand, and a responsibility to provide a common ground for this diversity, on the other. It is one thing to collect and digitize large quantities of memorial artifacts; it is quite another to display them in ways that stimulate not only spectatorship but also meaningful participation. Although online interactivity has been extolled for its potential to foster communitarian intimacy, it is necessary to ask what kind of exchange actually occurs - whether it indeed creates bridges between demographically and politically diverse audiences or promotes balkanization.

\section{Between Archive and Public Participation: The September 11 Digital Archive}

11 September 2001 became deeply etched in collective imagination not only because of the brutality of the terrorist attacks and the magnitude of human loss, but also because it was one of the most mediated disasters in history. Broadcast live on television, the sudden collapse of the World Trade Center towers was witnessed by a global audience. Yet mainstream media were not the only narrators of the unfolding drama of those tragic events and their aftermath. Thousands of people, armed with digital cameras and personal computers, were 
recording history and reporting it on the internet. In Dan Gillmor's description, "Another kind of reporting emerged during those appalling hours and days. Via e-mails, mailing lists, chat groups, personal web journals - all nonstandard news sources - we received valuable context that the major American media couldn't, or wouldn't, provide" (x).

Like grassroots journalism, the proliferation of memorial and discussion websites created in response to the trauma of 11 September 2001 and its aftermath pointed to the diversity and robustness of vernacular expression. Memorializing online was often an extension of the spontaneous process begun in the streets, squares, and train stations of New York City and Washington, D.C. Thousands of ephemeral artifacts from posters and graffiti to makeshift memorials filled public spaces, interrupting quotidian time and space of city life and creating a vivid counterpoint to mainstream media coverage. These unregulated displays of mourning, sympathy, pride, and protest not only represented a range of responses to the events - "intervening into the rhythm of the metropolis, the vernacular utterance of street memorials jolted lunch-hour pedestrians and commuters into realizing the significance of public spaces" (Haskins and DeRose 383). City residents, commuters, and tourists alike were made into witnesses of history as it was unfolding not on television or front pages of newspapers but directly in front of them. This liminal experience momentarily transformed a collection of passersby into a community of people who were, to paraphrase S. Michael Halloran (5), selfconsciously present to each other as well as to the spontaneous spectacle that brought them together. Before commemorative process migrated to cyberspace, it was actively experienced by thousands of people as they witnessed and contributed to the ephemeral tableau of vernacular gestures.

When temporary memorials and posters of missing began to be removed, many museums and organizations stepped in to preserve these and other ephemera of $9 / 11$ for posterity in order to add them as historical evidence to an already ample set of individual and corporate efforts to memorialize the victims of the attacks. The September 11 Digital Archive, organized by the American Social History Project at the City University of New York and the Center for History and New Media at George Mason University and now supported by the Library of Congress, represents a comprehensive attempt to "collect, preserve and present the history of September 11 attacks" (The September 11 Digital Archive). The Archive's stated purpose summarizes its desire to act as a mediator of a historical event as it was witnessed by regular people, to provide a well-sorted repository of materials for future historians, and to furnish a space where the 
disparate experiences and reactions could be relived and reflected on. Accordingly, the following discussion of the Archive will focus on these three aspects of its mission - to collect, to organize, and to display - in light of this article's concern with the promises of "digital memory."

"The utterly objective exhibition, like the completely unmediated photograph, is a phantasm" (Livingston and Beardsley 105). Archivists and museum curators always mediate between the artifacts they choose for display and their audiences but rarely do they explicitly acknowledge their own motives or recognize the role that visitors play in parsing an exhibit's narrative. As Bruce Ferguson argues, "Exhibitions are publicly sanctioned representations of identity, principally, but not exclusively, of the institutions which present them. They are narratives which use art objects as elements in institutionalized stories that are promoted to an audience" (9). For example, the Museum of the City of New York, one of the institutions that participated in salvaging ephemeral artifacts of 9/11 for posterity, organized an exhibit of these objects on the first anniversary of the attacks to "underscore the role of museums as stewards of the nation's stories and as special places where communities can examine and reaffirm our basic freedoms" (qtd in Haskins and DeRose 384).

It is therefore noteworthy that the organizers of the September 11 Digital Archive not only "exhibit [their] intention" but also show their awareness of being "only one of three agents" in the field of exhibition (the other two being the maker of objects on display and the viewer) (Baxandall 39). In so doing, they do not promote a univocal, selfaggrandizing narrative. Their goal, instead, is to "foster some positive legacies of those terrible events by allowing people to tell their stories, making those stories available to a wide audience, providing historical context for understanding those events and their consequences, and helping historians and archivists improve their practices based on the lessons we learn from this project" ("About this Site").

Unlike traditional exhibitions, where the curator often exercises full control over the selection of materials, the September 11 Digital Archive epitomizes inclusiveness, which is made possible in no small degree by the interactive capacities of electronic media. The Archive's "Contributor Information" link welcomes submissions in multiple forms and media (stories, e-mails, and images) and allows for participation by anyone who had been touched by the events of 11 September. In particular, the wording of answers to frequently asked questions invites collaboration, positioning audience members as active participants in the unfolding of history regardless of their age, nationality, or location on the day of the attacks. For example, those who may have doubted their story's importance because they 
were not at Ground Zero, the Pentagon, or in Pennsylvania, were reassured as follows: "Please! We want to hear from you. Your experiences need not have been at or near the directly affected locations, not [sic] do they need to be particularly heroic or harrowing tales. They can be short or much longer personal reminiscences about how you or the people you knew were affected by 9/11" "“Contributor Information"). Foreigners, too, were encouraged to contribute to the archive: "September 11 was an event that evoked many kinds of responses in many parts of the world. The internet is similarly a global phenomenon. As such, we are eager to receive contributions of all kinds from all parts of the world" "Contributor Information").

The Archive's strategy of democratic openness yielded a plethora of submissions, especially in the form of personal stories and images (both still and moving), which reached nineteen thousand and three thousand, respectively. In addition to these, the archive organized quantities of already existing individual, corporate and government websites, documents and online collections related to 11 September and its aftermath. Finally, in a section "Frequently Asked Questions about the September 11 attacks" it provided links to a step-by-step account of the event by the New York Times.

In its sprawling totality, this collection of stories, images, and points of view reflects the unsettled and still evolving quality of public memory of the 9/11 trauma. Although mainstream media accounts assembled by the Archive provide a factual overview of the events themselves, personal stories, photo essays, and artwork present a motley tapestry of sentiments and attitudes in response to the events. They echo the spontaneous vernacular commemoration begun in public spaces in the days after the attacks as well as testify to the connection between privately shaped memories and those furnished for public consumption by mainstream media.

Individual stories, arranged in reverse chronological order by the date of submission (similar to the way entries are displayed on electronic discussion lists), reveal a mix of the extraordinary and the banal. On the one hand, family members tell of their loved ones who perished, survivors recount the circumstances of their escape from the Twin Towers or the Pentagon, and volunteers relate their experiences of helping rescue and cleaning crews at Ground Zero or working at hospitals and blood banks. On the other hand, entry after entry describes its author's memory of television coverage of the terrorist attacks. Many of these register their shock at realizing that what they were watching was not an action movie but a live broadcast.

Although scores of stories simply recall their authors' first emotional reactions - disbelief, terror, and sympathy for victims and their 
families are the most common sentiments-some also go on to reflect on the meaning of the tragedy and its aftermath. A sense of vulnerability and loss pervades many entries, especially those by schoolchildren, for whom 11 September was the first exposure to organized violence on a large scale. As one high school student puts it, "Sometimes we take things for granted and my generation really didn't know what it felt like to be under attack but now we do" (Pichoff). A ski patroller from Colorado recalls the confusion and misplaced jingoism that characterized the months after the attacks:

The desire to take revenge was very strong, although there seemed to be nobody to take revenge against. In this atmosphere calling French fries "freedom fries", or singing "God Bless America", were seen as dynamic actions rather than being auxiliary to the matter at hand, simply because it was unclear as to what, exactly, the matter at hand was. (Oien)

There are, of course, more emphatic statements that express politically polarized attitudes in support of or in opposition to the U.S. government's domestic and foreign policy in the wake of 9/11. For example, a Chicago businessman who stockpiled firearms in case U.S. residents of Middle-Eastern descent become "sleeper warriors" and take to the streets, intones:

In short order-our Commander in Chief, George W. Bush, did what needed to be done in a very pragmatic and reasonable way. He went about the job he had to do and now the evil people that brought terror to us - are either dead, terrified or on the run and in hiding. They may well attack again. But for every one of us they kill, we will bring the wrath of God down on them thousandfold. (Hiley)

On the other end of the spectrum, a college student who became an anti-war activist after 11 September, voices her anger at the Bush administration:

September 11th made clear to me the importance of challenging and criticizing our governments [sic] blind move to bomb and murder thousands of innocent Afghanistani, and soon, Iraqi citizens. When the towers first fell I was in a state of shock, but as I listened to President Bush's rhetoric (laced heavily with calls for American Manifest Destiny), I found myself enraged and energized for action. (Jaeger)

Similar to verbal accounts, images submitted to the Archive represent a collage of perspectives. Among still photographs, which 
dominate the category, many document the devastation of Ground Zero and the neighborhoods around it, the recovery and clean-up work of the police and firefighters, and the proliferation of missing posters and impromptu remembrance shrines around New York City and the country. Some pictures capture the sights familiar to many through mainstream media coverage, such as the smoldering pile of wreckage that used to be the World Trade Center, whereas others focus on smaller details of the changed landscape, such as a poison dust warning posted in a Tribeca park near North Tower days after 9/11 (Vogler) or a Burger King that became a makeshift triage center (Occi).

Photographic entries often "voice" their authors' rhetorical intent, clarified by captions or short narratives. These commentaries tend to situate their subjects within some narrative frame, casting the events in a different light depending on the author's attitude. For instance, an image depicting a unit of National Guardsmen arriving at the World Trade Center site on 12 September is titled "Redeemers" (G. N. Miller) and as such contributes to a narrative of heroic sacrifice, which came to dominate the memory of $9 / 11$ as it has been constructed in mainstream U.S. culture in the following years. A narrative of a community coming together to grieve and remember is reflected in captions accompanying photographs of makeshift memorials, as in the one describing the temporary shrine in Union Square Park just twenty blocks from Ground Zero: "Every day, all day hundreds of people would gather" (Selders). Some authors attempt to account for the presence of revenge symbolism that dotted the landscape in the weeks following the tragedy. Commenting on the picture of a life-size doll of Osama bin Laden that was hanging by its neck out of a window of a house in Massachusetts, the photographer explains:

For the last eight years I have driven by Wallaston Beach in Quincy, Massachusetts on my way to work. A couple of days after 9/11 this appeared on one of houses along the beach. It was an erie [sic] image considering that you can watch planes take off and land from Logan airport at the beach. They fly right over-head. (Anonymous)

A dissenting anti-war narrative is represented by a submission called "Liberty Street Protest," whose author interprets the significance of a Liberty Street building whose windows displayed "No War" signs and peace symbols:

Overlooking the memorial plaques and area where most tourists and onlookers from around the world visit when they want to see the 
emptiness that is now Ground Zero and the WTC site as well as pay their respects. Conceived by local artist Glen E. Friedman, ... to let people of the world know that New Yorkers, who live so close to the actual destruction of $9 / 11 / 01$, do not agree with the "War on Terror" being waged in their name. (Dominguez)

The most prevalent narrative by far, however, is that of nostalgia for the World Trade Center and the post-industrial utopia it symbolized. Dozens of people sent in pictures of themselves and their family members photographed against the panoramic backdrop of the Manhattan skyline anchored by the Twin Towers. Criticized as the epitome of bad urban planning and architectural hubris during their lifetime, in their haunting absence the towers became beloved martyrs whose resurrection was viewed by many as essential to the restoration of New York City and the old world order.

In gathering together these disparate fragments of post-9/11 discourse, the Archive offers a panoramic view of the fractious cacophony of public expression that cannot be accommodated by a permanent, professionally designed memorial. Cultural geographer Kenneth Foote stresses the difficulty of constructing such a memorial to $9 / 11$ because of "the magnitude of the losses, the diversity of the victims, and the fact that the entire nation feels it has a stake in the commemorative process" (344). Although a physically tangible memorial is necessary, a virtual space such as the one provided by the Archive can play a crucial role in "forcing emotion and competing interpretations into the open" (Foote 343). By granting the authority to determine what's important (or appropriate) to individual contributors, September 11 Digital Archive refrains from taking sides and imposing closure upon the audience's interpretation of the different narratives. And, by allowing readers to continue submitting their stories and images, the Archive acknowledges that public memory is, in fact, an evolving process.

Beyond providing a forum for public expression, the Archive aims to offer a usable set of materials for professional historians who will revisit 11 September in the future. Toward this end, the collection is sorted and organized by medium and subject matter, allowing one to search through the cornucopia of submissions and links. Brief annotations describe many an item's content and occasionally indicate whether certain entries might offend some visitors, as in the case of several digital animation submissions that revel in the fantasy of violent retaliation against Osama bin Laden and al Qaeda. In other instances, the Archive's wording more explicitly distances its professional agenda from those of its many sources: "The September 11 
Digital Archive collects reports, studies, and white-papers written by a variety of organizations and institutions in response to the September 11, 2001 attacks and the public reaction to them. The Archive gathers and presents these items to preserve the historical record. These materials do not necessarily reflect the opinions and views of the Archive or its staff."

Perhaps the clearest sign of the Archive's desire to assert its status as a steward of history while allowing unrestricted public participation can be seen in the effort to distinguish between fact and fabrication. At the bottom of each individual submission, whether it's e-mail, story, or image, one finds a highlighted question, "How do I know that this item is factual"? Clicking on the question leads one to a manifesto of sorts that signals a tension between the Archive's populist commitment to grassroots history making and its professional obligation to maintain impartial factuality:

\begin{abstract}
Every submission to the September 11 Digital Archive - even those that are erroneous, misleading, or dubious - contributes in some way to the historical record. A misleading individual account, for example, could reveal certain personal and emotional aspects of the event that would otherwise be lost in a strict authentication and appraisal process. That said, most people who take the time to submit something to the September 11 Digital Archive share the goal of its organizers - that is, to create a reliable and permanent record of responses to the 9/11 attacks - and therefore most contributions are authentic. Nevertheless, as with any historical sources (including, for example, newspaper accounts), there are always questions about reliability, and all researchers need to evaluate their sources critically. It is for this reason that the Archive harvests metadata from every contributor-including name, email address, location, zip code, gender, age, occupation, date received - and suggests that these metadata be examined in relation to one another, in relation to the content of the submission, and in relation to other authenticated records. Sound research technique is the basis of sound scholarship. ("Frequently Asked Questions")
\end{abstract}

The Archive thus fashions itself as a space of interplay between vernacular and official interests, between the lay public and trained historians. It is a balancing act, however, and reservations in the quoted passage ("That said," "nevertheless") indicate how delicately one must tread to employ popular memory as a source of professional history writing.

If in its role as a database of historical materials the Archive seeks to respect the authorial agency of contributors, in the role of a tour guide it strives to educate its audience while respecting its autonomy. 
As distinct from brick-and-mortar exhibitions, digital displays do not offer a spatially continuous sequence of artifacts but instead work by inviting one to choose an item for display from a menu. It is the viewer's own preferences and interests, then, that ultimately shape her experience, even though the Web designer is responsible for the range of her choices.

To guide visitors' exposure to the variety of sources in its vast repository, September 11 Digital Archive makes use of several display mechanisms. First, an interactive menu breaks down the collection into main categories - stories, e-mail, still images, moving images, audio, documents, and guide to websites. Clicking on any of these links conjures another subdivision; "moving images," for example, comprises video, digital animations, and image collections from groups and individuals. Annotations further aid the visitor in choosing which item to view. If one is inclined to browse through "digital animations," labels do not so much dictate how one should interpret their content but direct the visitor's attention by noting the satirical quality of certain entries or warning that "viewers may find the content of this digital creation offensive."

Leaving it up to the audience to decide how to proceed in their interaction with the objects on display, the Archive assigns the responsibility for the content of individual entries to their authors. In some cases, the audience reaction to certain submissions was so voluminous and polarized that their authors were compelled to add a formal reply. Thus, the author of "America Attacked 9/11," a digital creation that combined a tribute to victims and heroes of 11 September with a call for military retaliation, posted a form letter to answer his critics' objections:

Please don't e-mail me about trying to understand the folks that did this. I have no interest in understanding them. I want them dead. Don't email me about innocent people being accidently [sic] killed in a war zone. I am uninterested in their plight and if that sounds cold, go review my website again. None of THOSE people were at war on 11 September and they are not casualties of war. They were murdered. I don't want their murderers treated as war criminals; I want them treated as they are - subhuman criminals who committed crimes against humanity. I don't want to hug them, analyze them or anything other than annihilate them. Wipe them off the face of the earth. (Golding)

The letter not only reveals the author's frame of mind but also points to a deep political division that marked public response to the U.S. government's policies in the aftermath of the attacks. After all, "depending on your political inclinations, the events of September 11, 
2001 were either unique or inevitable, richly deserved or entirely unprovoked, a predictable product of generations of conflict or the dawn of an entirely new age" (Mandel). The Archive's judiciously neutral stance with regard to submissions' content, in this case, allows for a clash of these political perspectives, ignited by one contributor's inflammatory rhetoric.

Still, the Archive conspicuously exercises its control over the arrangement of items on display to draw attention to entries that may otherwise go unnoticed. Similar to temporary special exhibits mounted by regular museums, September 11 Digital Archive presents "featured items" that underscore its public mission to give voice to underrepresented views. The main page, for example, highlights experiences of Chinatown residents, "largely neglected by national media following 9/11," by providing a link to a collection "Ground One: Voices from Post-911 Chinatown." Under the "Documents" rubric, the featured item is "American Backlash," a "report documenting press coverage of bias incidents and violent hate crimes that occurred in the first week after the September 11 attacks." Until the fifth anniversary of the attacks, the video collection gave center stage to a film featuring interviews with Arab-American residents of Bay Ridge, Brooklyn ("Arab American Responses"), after which a commemorative montage "September 11 Hero Tribute" took the spotlight. The "featured item" strategy, then, can be a mechanism for leveling the playing field by allowing politically marginalized groups to have their say. Ironically, in so doing the Archive is trying to balance its open submission policy that generated plenty of politically incorrect and even offensive material in the name of popular participation.

Perhaps because of the tension between its commitment to unbridled populism, on the one hand, and political fairness on the other, the Archive seems reluctant to lend its curatorial credibility to a particular way of commemorating 11 September. An example of this seeming objectivity is an "interactive map" of Manhattan unveiled on the fourth anniversary of 9/11 attacks. The Archive selected from its collection photographs and stories that captured the attacks against the World Trade Center and overlaid them on the map of Manhattan. Each photograph is represented by a blue marker and each story by a red marker. Visitors can click on them to relive, in painful detail, the events of that fateful day from the perspective of people who witnessed them first hand. The virtue of this display is that it presents, in a visually compelling and dynamic way, images and accounts that until then had been separate fragments of a larger story. Seeing the burning towers of the World Trade Center photographed from various vantage points and reading accounts of commuters, train 
operators, and policemen gives one a sense of the event as it unfolded. However, the display offers little beyond the now familiar spectacle of impending devastation, freezing in memory the moment before the towers' collapse. Reproduced repeatedly in various news media, the image of the World Trade Center still standing became iconic in the weeks and months following the attacks. As Barbie Zelizer explains its rhetorical power,

Not only did the images [of the towers] offer the appropriate degree of contingency for a message too harsh to be seen with the brute force of reality's depiction.... But the image also cut - and depicted - the story at precisely its most powerful moment, pushing spectators to recognize what came later while allowing them to prolong the experience of what had been before. The images hence created a space of (im)possibility, whereby spectators were able to linger in a moment when the full scope of the tragedy was not yet upon them. (178-79)

Focusing on this moment in an anniversary display, then, the Archive assimilated its audience's contributions into the mainstream media's strategy that can be described as a symbolic refusal to come to terms with the events of 11 September.

\section{Conclusion}

This article began with a premise that any discussion of public memory ought to take into account the issue of mediation. The rising popularity of the internet as a medium of both private remembrance and public commemoration calls for a reconsideration of traditional distinctions between official memory, embodied by "compensatory organs of remembrance" such as memorials, monuments, and museums, and vernacular forms of memory that depend on active communal participation. Online memorializing, thanks to the technology's capacity for virtually unlimited storage and potential to engage many diverse audiences in content production, appears to mitigate against the ideological ossification associated with official memory practices and the fragility of vernacular memorial gestures.

At the same time, in exploring the internet's promise as a medium of public memory, it is important to realize that the contemporary Western obsession with recording traces of the past is an ambivalent cultural trend-it signals not only the "democratization" of memory work but also the acceleration of amnesia. Moreover, the very features of electronic communication that make the technology friendly to popular participation in cultural politics can also abet political fragmentation. 
As the most comprehensive effort to collect, organize, and display discursive traces of the momentous historical event commonly referred to as 9/11, the September 11 Digital Archive illustrates both the virtues and limitations of digital memory. Launched by professional historians, it is presented as an inclusive collection of contributions from both individuals and institutions. According to the Archive's director, Tom Scheinfeldt, there is a direct link between the size of digital storage and its democratic potential: "Unlike traditional 'brick and mortar' archives, there are no physical limits to the size of the September 11 Digital Archive's collection. If it needs to expand, it just adds more disk space. This means that no digital object is too trivial for the Archive to accept" ("Memories"). Indeed, the strategy of defining any submission related to 9/11 as "historical record" allowed the Archive to solicit and preserve a vast and diverse set of stories, images, and points of view that otherwise would have been lost or dispersed in cyberspace and private archives.

At first glance, there is no downside to inclusiveness: the Archive encourages ordinary people to participate in the production of public memory, furnishes future historians with a wealth of data, and generates a robust multiplicity of perspectives on the same event. Preservation of large quantities of digitized materials does not translate into a usable past, however. The task of interpreting this "burgeoning dossier," to use Nora's phrase, is decentralized and entrusted to the Archive's users, be they future professional historians or lay visitors. The Archive gives minimal guidance to either group: historians are admonished to distinguish between fact and fabrication when sifting through the submissions; visitors are reminded to pay attention to underrepresented voices and to be wary of voices that may offend them. There is no other mechanism, however, for encouraging the audience to explore views different from their own, in the manner that pedestrians in the streets of New York City were in the weeks following 11 September.

Such decentralized approach to historical research and remembrance may indeed be a self-conscious reaction against the traditional dictatorial role of official institutions of memory. By allowing users to participate in the shaping of the historical record and by enabling them to take charge of their journey through its collection, the Archive undoubtedly preempts possible accusations of professional elitism and political bias. Although making multiple fragments of the $9 / 11$ discourse publicly visible and accessible, however, this approach also shifts the burden of active remembrance to individuals and groups, effectively disavowing the public nature of the enterprise. 


\section{Notes}

${ }^{1}$ The narrative orientation of archives and museums is evident both in their acquisition policies and display strategies. On the archive's role in constructing a connection between past and present, see Brothman. Mieke Ball similarly argues that what is being collected is guided by what story the objects on display can tell.

${ }^{2}$ Nora distinguishes between lieux de memoire, sites of memory, and milieux de memoire, environments of memory, noting that the former have largely displaced the latter "by virtue of the de-ritualization of our world" (12).

${ }^{3}$ See Savage on official commemorative practices after the Civil War and Bodnar on the tension between official and vernacular commemorations in the twentieth century. Foote's study of how Americans have marked sites of tragic and violent events in the last three centuries also suggests that the monumental veneration of heroes and martyrs has been the preferred method of dealing with traumatic memories.

${ }^{4}$ Blair, Jeppeson, and Pucci interpret the Vietnam Veterans Memorial as a prototype of postmodern memorializing, given its openness to multiple interpretive gestures, its sensitivity to its environment, and its interrogative, critical stance.

${ }^{5}$ Manovich maintains that "to call computer media 'interactive' is meaningless - it simply means stating the most basic fact about computers" (55). He further cautions, "when we use the concept 'interactive media' exclusively in relation to computer-based media, there is the danger that we will interpret 'interaction' literally, equating it with physical interaction between a user and a media object (pressing a button, choosing a link, moving the body), at the expense of psychological interaction. The psychological processes of filling-in, hypothesis formation, recall, and identification, which are required for us to comprehend any text or image at all, are mistakenly identified with an objectively existing structure of interactive links" (57). Upon reviewing recent literature on "interactivity" and synthesizing the various definitions of it, Kiousis suggests that interactivity is both a media and psychological factor that varies across communication technologies, communication contexts, and people's perceptions.

${ }^{6}$ At the same time, historians and archivists are concerned that digital data in particular lacks durability. As Web enthusiasts Daniel Cohen and Roy Rosenzweig point out, "we are rapidly losing the digital present that is being created because no one has worked out a means of preserving it."

${ }^{7}$ Noting "passivity" (the downside of "interactivity") as one of the major challenges to doing history online, Cohen and Rosenzweig paraphrase literary critic Harold Bloom who argues that "whereas linear fiction allows us to experience more by granting us access to the lives and thoughts of those different from ourselves, interactivity only permits us to experience more of ourselves."

\section{References}

Anonymous. Image \#2603. The September 11 Digital Archive. 7 September 2004. Retrieved from http://911digitalarchive.org/images/details2603

Ball, Mieke. "Telling Objects: A Narrative Perspective on Collecting." The Cultures of Collecting. Eds. John Elsner and Roger Cardinal. Cambridge: Harvard UP, 1994: 97-115.

Baxandall, Michael. "Exhibiting Intention." Exhibiting Cultures: The Poetics and Politics of Museum Display. Eds. Ivan Karp and Steven D. Lavine. Washington: Smithsonian Institution Press, 1991. 33-41.

Blair, Carole, Martha S. Jeppeson, and Enrico Pucci. "Public Memorializing in Postmodernity: The Vietnam Veterans Memorial as Prototype." Quarterly Journal of Speech 77 (1991): 263-288. 
Blood, Rebecca. "Weblogs: A History and Perspective." Rebecca's Pocket.7 September 2000. Retrieved July 10, 2006 from http://www.rebeccablood.net/essays/weblog_ history.html

Bodnar, John. Remaking America: Public Memory, Commemoration, and Patriotism in the Twentieth Century. Princeton, NJ: Princeton UP, 1992.

Brothman, Brien. "The Pasts That Archives Keep." Archivaria 51 (2001): 48-80.

Cohen, Daniel J. and Roy Rosenzweig. Digital History: A Guide to Gathering, Preserving, and Presenting the Past on the Web. Philadelphia: U Pennsylvania P, 2005.

Dominguez, Vida. Image \#2673. The September 11 Digital Archive.12 October 2004. Retrieved from http://911digitalarchive.org/images/details/2673

Duncan, Carol. "Art Museums and the Ritual of Citizenship." Exhibiting Cultures: The Poetics and Politics of Museum Display. Eds. Ivan Karp and Steven D. Lavine. Washington: Smithsonian Institution Press, 1991. 88-103.

Ferguson, Bruce W. "Exhibition Rhetorics: Material Speech and Utter Sense." Thinking About Exhibitions. Eds. Reesa Greenberg, Bruce W. Ferguson, and Sandy Nairne. London: Routledge, 1996. 175-190.

Foote, Kenneth E. Shadowed Ground: America's Landscapes of Violence and Tragedy. Revised Edition. Austin, TX: U of Texas P, 2003.

Foot, Kristen, Barbara Warnick, and Steven M. Sneider. "Web-Based Memorializing after September 11: Toward a Conceptual Framework." Journal of ComputerMediated Communication 11 (2005): article 4. Retrieved June 4, 2006 from http:// jcmc.indiana.edu/vol11/issue1/foot.html

Gillis, John R. "Memory and Identity: A History of a Relationship." Commemorations: The Politics of National Identity. Ed. John R. Gillis. Princeton: Princeton UP, 1994. 1-24.

Gillmor, Dan. We the Media: Grassroots Journalism by the People, For the People. Sebastopol, CA: O’Reilly Media, 2004.

Golding, Steve. "Creator's Statement." The September 11 Digital Archive. 20 February 2002. Retrieved from http://911digitalarchive.org/moving/moving_collections.html

Gronbeck, Bruce E. "Citizen Voices in Cyberpolitical Culture." Rhetorical Democracy: Discursive Practices of Civic Engagement. Eds. Gerard A. Hauser and Amy Grim. Mahwah, NJ: Lawrence Erlbaum, 2004.

Gurak, Laura J. Cyberliteracy: Navigating the internet with Awareness. New Haven: Yale UP, 2001.

Halloran, S. Michael. "Text and Performance in a Historical Pageant: Toward a Rhetoric of Spectacle." Rhetoric Society Quarterly 31 (2001): 5-17.

Haskins, Ekaterina V. and Justin P. DeRose. "Memory, Visibility, and Public Space: Reflections on Commemoration(s) of 9/11." Space and Culture 6 (2003): 377-393.

Hawkins, Peter S. "Naming Names: The Art of Memory and the NAMES Project AIDS Quilt." In Thinking About Exhibitions. Eds. Reesa Greenberg, Bruce W. Ferguson, and Sandy Nairne. London: Routledge, 1996. 133-155.

Hiley, Richard. Story \#10532. The September 11 Digital Archive.11 April 2004. Retrieved from http://911digitalarchive.org/stories/details/10532

Huyssen, Andreas. Twilight Memories: Marking Time in a Culture of Amnesia. New York: Routledge, 1995.

Jaeger, Elizabeth. Story \#8483. The September 11 Digital Archive.17 October 2002. Retrieved from http://911digitalarchive.org/stories/details/8483

Kiousis, Spiro. "Interactivity: A Concept Explication." New Media and Society 3 (2002): 355-383.

Landow, George. "Hypertext as Collage-Writing." The Digital Dialect. Ed. Peter Lunenfeld. Cambridge, MA: The MIT Press, 2000. 150-170. 
Mandel, Naomi. "To Claim the Mandane." Journal of Mandane Behavior 3.3 (2002). Retrieved 10 July 2006 from http://mundanebehavior.org/issues/v3n3/mandel33.htm

Manovich, Lev. The Language of New Media. Cambridge: MIT Press, 2001.

Miller, Carolyn R. and Dawn Shepherd. "Blogging as Social Action: A Genre Analysis of the Weblog." Into the Blogosphere: Rhetoric, Community, and Culture of Weblogs. Eds. Laura Gurak, Smiljana Antonijevic, Laurie Johnson, Clancy Ratliff, and Jessica Reyman. Retrieved July 10, 2006 from http://blog.lib.umn.edu/blogosphere/ blogging_as_social_action_a_genre_analysis_of_the_weblog.html

Miller, G. N. Image \#2757. The September 11 Digital Archive. 1 June 2005. Retrieved from http://911digitalarchive.org/images/details/2757

Nora, Pierre. "Between Memory and History: Les Lieux de Memoire." Representations 26 (1989): 7-25.

Occi, Jim. Image \#1760. The September 11 Digital Archive. 14 November 2002. Retrieved from http://911digitalarchive.org/images/details/1760

Oien, Niles. Story \#11163. The September 11 Digital Archive. 17 November 2004. Retrieved from http://911digitalarchive.org/stories/details/11163

Pichoff, Lisa. Story \#11549. The September 11 Digital Archive. 24 June 2005. Retrieved from http://911digitalarchive.org/stories/details/11549

Savage, Kirk. Standing Soldiers, Kneeling Slaves: Race, War and Monument in Nineteenth-Century America. Princeton, NJ: Princeton UP, 1999.

Scheinfeldt, Tom. "Memories: September 11 Digital Archive." 9 September 2002. Retrieved on 10 July 2006 from http://hnn.us/articles/959html

Selders, Paul. Image \#1742. The September 11 Digital Archive. 3 November 2002. Retrieved from http://911digitalarchive.org/images/details/1742

Selnow, Gary W. Electronic Whistle-Stops: The Impact of the internet on American Politics. Westport, CT: Praeger, 1998.

Sturken, Marita. "The Wall, the Screen, and the Image: The Vietnam Veterans Memorial." In The Visual Culture Reader. Ed. N. Mirzeoff. London: Routledge, 1998. 163-178.

Vogler, David. Image \#2691. The September 11 Digital Archive. 1 November 2004. Retrieved from http://911digitalarchive.org/images/details/2691

Warnick, Barbara. Critical Literacy in a Digital Era: Technology, Rhetoric, and the Public Interest. Mahwah: Erlbaum, 2002.

- "Looking to the Future: Electronic Texts and the Deepening Interface." Technical Communication Quarterly 14 (2005): 327-333.

Wodiczko, Krzysztof. Critical Vehicles: Writings, Projects, Interviews. Cambridge, MA: MIT Press, 1999.

Zelizer, Barbie. "The Voice of the Visual in Memory." Framing Public Memory. Ed. Kendall R. Phillips. Tuscaloosa: U of Alabama P, 2004. 157-186. 
Copyright of RSQ: Rhetoric Society Quarterly is the property of Routledge and its content may not be copied or emailed to multiple sites or posted to a listserv without the copyright holder's express written permission. However, users may print, download, or email articles for individual use. 